\title{
Postoperative analgesia is not different after local vs systemic administration of meloxicam in patients undergoing inguinal hernia repair
}

[L'analgésie postopératire ne diffêre pas après l'administration locale ou intraveineuse de méloxicam pour une herniorraphie inguinale]

Janne Rømsing MSC PHARM PhD, ${ }^{*}$ Steffen Mysager MD, $†$ Peter Vilmann MD DMSC,‡ Jesper Sonne MD DMSC, $\$$ Niels Erik Larsen MSC CHEM, $\$$ Doris Østergaard MD $†$

Purpose: To distinguish between local and systemic drug effects, we compared pain scores, analgesic consumption and plasma concentrations after local vs iv administration of meloxicam $7.5 \mathrm{mg}$ in patients with inguinal hernia repair.

Methods: In a double-blind, randomized study 56 patients received either local or iv meloxicam $7.5 \mathrm{mg}$. Postoperative pain was assessed with a visual analogue scale (VAS) at rest, on mobilization, and on coughing, the need for supplementary analgesics (fentanyl iv and/or acetaminophen-codeine tablets) was recorded, and blood samples were drawn during $24 \mathrm{hr}$ after meloxicam administration.

Results: No significant differences were found between groups with respect to pain scores, or in the consumption of supplementary analgesics. Following local application of meloxicam, the peak plasma concentration $\left(C_{m a x}\right)$ of $0.5 \pm 0.2 \mathrm{mg} \cdot \mathrm{L}^{-1}$ achieved after 1.8 $\pm 0.5 \mathrm{hr}$ was much lower than the $C_{\text {max }}$ of $2.5 \pm 0.9 \mathrm{mg} \cdot \mathrm{L}^{-}$ achieved immediately after iv administration $(P<0.05)$. Mean meloxicam plasma concentration after infiltration was significantly lower than after iv doses for the first three hours after administration $(P<0.05)$

Conclusion: We showed no differences in pain scores and ana gesic consumption between local and iv administration of melox cam $7.5 \mathrm{mg}$ during the first $24 \mathrm{hr}$ after herniorrhaphy, while plasma concentration of meloxicam was lower after local administration. These results indicate a lack of difference in pain relief after concentrating meloxicam at the hernia wound or after achieving high blood levels rapidly (iv). Local administration of meloxicam may confer an advantage over systemic administration by eliciting lower incidences of systemic adverse effects.
Objectif: Distinguer les effets médicamenteux locaux et systémiques en comparant les scores de douleur, la consommation analgésique et les concentrations plasmatiques après l'administration locale ou iv de 7,5 mg de méloxicam chez des patients qui subissent une herniorraphie inguinale.

Méthode : Il s'agit d'une étude randomisée et à double insu auprès de 56 patients qui ont reçu 7,5 mg de méloxicam local ou intraveineux. La douleur postopératoire a été évaluée avec une échelle visuelle analogique (EVA) au repos, pendant le mouvement et la toux. Le besoin d'analgésie complémentaire (fentanyl iv et/ou comprimés d'acétaminophène-codéine) a été enregistré et les échantillons sanguins prélevés pendant $24 \mathrm{~h}$ après l'administration de méloxicam.

Résultats : Aucune différence intergroupe significative n'a été trouvée quant aux scores de douleur ou à la consommation d'analgésique complémentaire. Après l'infiltration de méloxicam, la concentration plasmatique maximale (Cmax) de 0,5 $\pm 0,2 \mathrm{mg} \cdot \mathrm{L}^{-1}$ atteinte après I,8 $\pm 0,5 \mathrm{~h}$ a été plus faible que la Cmax de 2,5 $\pm 0,9 \mathrm{mg} \cdot \mathrm{L}^{-}$ atteinte immédiatement après l'administration iv $(P<0,05)$. Pendant les trois premières heures après l'administration de méloxicam, la concentration plasmatique moyenne était plus basse après l'infiltration qu'après les doses iv $(P<0,05)$.

Conclusion : Pendant les 24 premières heures suivant une herniorraphie, les douleurs et la consommation d'analgésique n'ont présenté aucune différence après l'administration locale ou iv de $7,5 \mathrm{mg}$ de méloxicam. Mais, la concentration plasmatique de méloxicam a été plus faible après l'administration locale. La douleur n'est pas mieux soulagée avec le méloxicam concentré au site de la plaie herniaire ou administré par voie iv permettant d'atteindre rapidement des concentrations plasmatiques élevées. Par ailleurs, l'infiltration pourrait réduire davantage l'incidence d'effets secondaires généralisés.

From the Department of Pharmaceutics, ${ }^{*}$ The Royal Danish School of Pharmacy, Copenhagen; the Department of Anesthesiology, the Department of Surgical Gastroenterology, and the Department of Clinical Pharmacology, \$ Gentofte University Hospital, Hellerup, Denmark.

Address correspondence to: Dr. Janne Rømsing, Department of Pharmaceutics, The Royal Danish School of Pharmacy, 2

Universitetsparken, DK-2100 Copenhagen, Denmark. Phone: +45 3530 62 39; Fax: +45 353060 30; E-mail: jr@dfh.dk

Accepted for publication June 28, 2001.

Revision accepted August 2, 2001. 
$\longrightarrow$

HE efficacy of nonsteroidal anti-inflammatory drugs (NSAIDs) for postoperative pain relief is well recognized but may be accompanied by undesirable systemic effects.

NSAIDs inhibit the activity of cyclooxygenases (COX).

It has been suggested that the well-known adverse effects of NSAIDs are caused by inhibition of COX-1, whereas inhibition of COX-2 is the mechanism by which NSAIDs exert their anti-inflammatory, antipyretic, and analgesic effects. ${ }^{1}$ This is the rationale for the development of new, COX-2 selective NSAIDs, because the NSAIDs used so far preferentially inhibit COX-1.2

Meloxicam is a relatively new NSAID which has consistently demonstrated selective COX-2 inhibition. ${ }^{3}$ It shows similar efficacy to standard NSAIDs but has an improved tolerability profile, consistent with the finding of COX-2 selectivity. Meloxicam is at the moment the only COX-2 selective NSAID developed for parenteral administration. Meloxicam is suitable for once daily administration, because of its elimination half-life $\left(t_{1 / 2}\right)$ of approximately $20 \mathrm{hr}$ and it is well tolerated with respect to local and systemic reactions. ${ }^{4}$ The recommended dose of meloxicam is 7.5-15 mg every $24 \mathrm{hr}$. For postoperative pain, one study has shown a significant analgesic effect following administration of rectal meloxicam $15 \mathrm{mg}$ in patients after abdominal hysterectomy. ${ }^{5}$

Some suggest a peripheral-central synergistic action of NSAIDs that varies depending on the particular NSAID and on the presence or absence of an inflammatory process. ${ }^{6}$ NSAIDs inhibit prostaglandin synthesis in peripheral tissues and, therefore, administration of a dose of NSAID locally would be expected to produce more intense analgesia than if the same dose was given systemically.

A small number of studies have investigated the postoperative analgesic effect of wound infiltration (WI) with NSAIDs compared with systemic administration and the results are discordant ${ }^{7-12}$ with three studies showing improved pain relief after intrawound administration ${ }^{7,11,12}$ and with another three studies showing no difference between intra-wound infiltration and systemic administration. ${ }^{8-10}$

In an effort to distinguish between local and systemic drug effects, we compared pain scores, consumption of supplementary analgesics and plasma concentrations of meloxicam $7.5 \mathrm{mg}$ after local infiltration and $i v$ administration in patients undergoing inguinal hernia repair.

\section{Methods}

Fifty-six patients, 18-65 yr of age, scheduled for elective inguinal herniorrhaphy were included in this dou- ble-blind, randomized study. Approval was given by the Regional Ethics Committee and the Danish Medicines Agency prior to study commencement and written informed consent was obtained from all patients. Patients were recruited from the Department of Surgical Gastroenterology, Gentofte University Hospital during the period August 1999 to October 2000. Patients were not included if they had a history of drug or alcohol abuse, chronic pain, daily intake of analgesics, known upper gastrointestinal bleeding, renal disease, asthma, hypersensitivity to meloxicam or any other NSAID, any bleeding disorder, or were unable to cooperate.

The study drugs were identical injection fluids of meloxicam $10 \mathrm{mg} \cdot \mathrm{mL}^{-1}$, or vehicle without meloxicam. The vehicle control (placebo) was prepared by the hospital pharmacy.

The patients received no premedication. General anesthesia was induced with fentanyl $2 \mu \mathrm{g} \cdot \mathrm{kg}^{-1}$ and propofol $2.5 \mathrm{mg} \cdot \mathrm{kg}^{-1} i v$. A laryngeal mask airway was inserted and anesthesia was maintained with propofol and oxygen/air.

The surgical techniques were open procedures, with or without extirpation of the hernial sac. Annulorrhaphy or a tension-free herniorrhaphy (Lichtenstein) with insertion of a polypropylene mesh were used for an indirect inguinal hernia. A tension-free herniorrhaphy (Lichtenstein) with insertion of a polypropylene mesh was used for a direct inguinal hernia.

At the end of surgery, prior to skin closure, patients were allocated randomly, on the basis of a computergenerated schedule, in a double-blind manner, to receive either surgical WI with $0.75 \mathrm{~mL}$ meloxicam 10 $\mathrm{mg} \cdot \mathrm{mL}^{-1}(7.5 \mathrm{mg}$ meloxicam) and $0.75 \mathrm{~mL}$ vehicle control iv or to receive $0.75 \mathrm{~mL}$ meloxicam iv and infiltration of the surgical wound with $0.75 \mathrm{~mL}$ vehicle control. The surgeon, who was blinded to the content of the study syringe, injected either meloxicam or vehicle in the subfascial layer of the inguinal canal and, simultaneously, the anesthesiologist administered the $i v$ injection of either vehicle or meloxicam. All patients were transferred to the same recovery room and observed by nursing staff experienced in postoperative pain treatment. Patients ingested two tablets of a fixed combination of acetaminophen $500 \mathrm{mg}$ plus codeine phosphate $30 \mathrm{mg}$ PRN every six hours for postoperative analgesia during the $24 \mathrm{hr}$ study period. If analgesia provided by the tablets was insufficient, as considered by the patient, fentanyl $1 \mu \mathrm{g} \cdot \mathrm{kg}^{-1} i v$ was administered on request. The patients received no other analgesics during the study.

Time from meloxicam administration to first analgesic request and the total number of doses required 
during the first six hours and $24 \mathrm{hr}$ after meloxicam administration were recorded. Postoperative pain was assessed by the patients using a visual analogue scale (VAS, $0 \mathrm{~mm}=$ no pain, $100 \mathrm{~mm}=$ worst pain imaginable) at rest, during mobilization from the supine to the sitting position, and during coughing at $1,1.5,2$, $2.5,3,4,5,6,10$, and $24 \mathrm{hr}$ after administration of meloxicam. The primary end-point of this study was pain (VAS score) during mobilization at six hours and the secondary end-point was the six hours' consumption of supplementary analgesics.

For the measurement of meloxicam plasma concentrations blood samples $(4 \mathrm{~mL})$ were drawn before and $1,3,5,10,30,45,60 \mathrm{~min}$ and $11 \frac{1}{2}, 2,2^{1 / 2}, 3,4,6$, and $24 \mathrm{hr}$ after drug administration. The blood was centrifuged and the plasma was frozen at $-20^{\circ} \mathrm{C}$ until assay

Meloxicam concentrations were measured by means of a high-performance liquid chromatography method (details available upon request). The calibration curve was linear in the range up to $10 \mathrm{mg} \cdot \mathrm{L}^{-1}$, with a limit of detection of $0.1 \mathrm{mg} \cdot \mathrm{L}^{-1}$. Intra-assay variations were $4.5 \%$ for $0.3 \mathrm{mg} \cdot \mathrm{L}^{-1}$ and $2.3 \%$ for $1.5 \mathrm{mg} \cdot \mathrm{L}^{-1}$. Interassay variations were $6.0 \%$ and $2.4 \%$ for concentrations $0.3 \mathrm{mg} \cdot \mathrm{L}^{-1}$ and $1.5 \mathrm{mg} \cdot \mathrm{L}^{-1}$, respectively.

Plasma concentration-time profiles were constructed. A 1-compartment model was used to analyze data (WinNonlin, Pharsight Corp., Cary, NC, 1998). The quality of fit of the pharmacokinetic model to the data was judged by visual examination of plots of observed $v s$ predicted concentrations.

Time to reach maximum concentration $\left(\mathrm{T}_{\mathrm{max}}\right)$, and maximum plasma concentrations $\left(\mathrm{C}_{\max }\right)$ were determined directly from the individual plasma concentration-time profiles. The area under the plasma drug concentration-time curve (AUC) $)_{0-\mathrm{t}}$ was estimated by the trapezoidal rule. The terminal elimination half-life $\left(t_{1 / 2}\right)$ was calculated using the equation: $t_{1 / 2}=\ln 2 / k_{e}$. The elimination rate constant $\left(\mathrm{k}_{\mathrm{e}}\right)$ is the slope of the terminal portion of the plasma concentration-time curve. Clearance (CL) after iv and clearance related to bioavailability $(\mathrm{CL} / \mathrm{F})$ after local administration, and volume of distribution $(\mathrm{V})$ after $i v$ administration and volume of distribution related to bioavailability $(\mathrm{V} / \mathrm{F})$ after local application were obtained from the 1-compartment analysis.

We set the acceptable risk of type 1 error at $5 \%$ and that of type 2 error at $20 \%$. With the smallest difference between mean values not to be overlooked $=2.5$, the necessary fixed sample size was calculated to be 22 patients in each group. Based on these values we decided to include 25 patients in each group. Excluded patients were replaced until 50 data sets were available for analysis.
Data are presented as mean values with their standard deviations and when appropriate as median values and ranges. Analysis of demographic data was performed by Chi-square test. Kruskal-Wallis nonparametric one-way analysis of variance was used to evaluate the differences in pain score. If multiple testing was performed, significant $P$ values were corrected with a Bonferroni factor for multiple comparisons. Duration of surgical procedure, time to first analgesic requirement, total six hours and $24 \mathrm{hr}$ analgesic requirements, and pharmacokinetic estimates, were analyzed by using one-way analysis of variance (ANOVA). The Fisher's exact test was used to compare the number of fentanyl doses. Statistical significance was defined as $P<0.05$.

\section{Results}

Sixty patients were considered for inclusion in the study but four did not want to participate. Of the 56 patients included, 27 patients were randomized to receive local infiltration of meloxicam and 29 patients received meloxicam as an iv injection. Six patients were excluded during the $24 \mathrm{hr}$ study period leaving 25 patients in each study group: two immediately after surgery (one patient in the local group because herniorrhaphy was not necessary, and one patient in the iv group because an analgesic other than prescribed in the study protocol was administered during surgery); two at three hours and one at four hours in the $i v$ group, and one at five hours in the local group due to alcohol intake or intake of an analgesic other than prescribed, respectively. There were no significant differences in patient characteristics and perioperative data between the two groups (Table I)

There were no statistically significant differences between groups for VAS pain scores at rest, during mobilization from the supine to the sitting position or during coughing at any time, although there was a trend towards reduced pain scores during mobilization and coughing after $2.5 \mathrm{hr}$ in the $i v$ group (Figure 1).

There were no significant differences between the local and the iv groups in the number of patients requesting supplementary fentanyl or in cumulative postoperative fentanyl requirements (zero to three hours). In the local infiltration group seven patients required fentanyl and the mean dose was $70 \mu \mathrm{g}$. In the $i v$ group five patients required fentanyl and the mean dose was $80 \mathrm{ug}$. Also, there was no difference between groups for the time from administration of meloxicam to the first request for fentanyl (Table II). There were no differences between the local and the iv groups in the number of patients requesting supplementary acetaminophen-codeine or for the cumulative aceta- 
TABLE I Demographic and perioperative data (number or median (range)). No significant differences between groups

\begin{tabular}{|c|c|c|}
\hline & \multicolumn{2}{|c|}{ Groups } \\
\hline & $\begin{array}{l}\text { Local } \\
\text { administration } \\
\text { of meloxicam } \\
7.5 \mathrm{mg}\end{array}$ & $\begin{array}{l}\text { iv injection } \\
\text { of meloxicam } \\
7.5 \mathrm{mg}\end{array}$ \\
\hline No. of patients included & 27 & 29 \\
\hline $\begin{array}{l}\text { No. of patients at the } \\
\text { end of surgery }\end{array}$ & 26 & 28 \\
\hline $\begin{array}{l}\text { No. of patients } 24 \mathrm{hr} \\
\text { after surgery }\end{array}$ & 25 & 25 \\
\hline $\operatorname{Sex}(M / F)$ & $25 / 1$ & $27 / 1$ \\
\hline Age (yr) & $51(25-65)$ & $52.5(19-65)$ \\
\hline Weight $(\mathrm{kg})$ & $78.5(61-97)$ & $73.5(60-100)$ \\
\hline Indirect/direct herniorrhaphy & $17 / 9$ & $21 / 7$ \\
\hline Open procedures & & \\
\hline Annulorrhaphy & 7 & 7 \\
\hline $\begin{array}{l}\text { Lichtenstein with } \\
\text { polypropylene mesh }\end{array}$ & 19 & 21 \\
\hline Duration of surgery (min) & $40(23-78)$ & $45(27-77)$ \\
\hline
\end{tabular}

TABLE II Postoperative analgesic requirements from 0 to $24 \mathrm{~h}$ after meloxicam administration (number or median (range)). No significant differences between groups

\begin{tabular}{|c|c|c|}
\hline & \multicolumn{2}{|l|}{ Groups } \\
\hline & $\begin{array}{l}\text { Local } \\
\text { administration of } \\
\text { meloxicam } 7.5 \mathrm{mg}\end{array}$ & $\begin{array}{l}\text { iv injection } \\
\text { of meloxicam } \\
7.5 \mathrm{mg}\end{array}$ \\
\hline \multicolumn{3}{|l|}{ Fentanyl iv } \\
\hline \multicolumn{3}{|l|}{$0-3 \mathrm{hr}$} \\
\hline No. of patients requesting & $7 / 26$ & $5 / 28$ \\
\hline No. of doses requested & 9 & 6 \\
\hline Time to first request $(\mathrm{min})$ & $42(20-125)$ & $55(11-180)$ \\
\hline \multicolumn{3}{|l|}{ Acetaminophen-codeine tablets } \\
\hline No. of patients requesting & $21 / 25$ & $22 / 25$ \\
\hline Doses requested & $1(0-3)$ & $1(0-2)$ \\
\hline \multicolumn{3}{|l|}{$0-24 \mathrm{hr}$} \\
\hline No. of patients requesting & $24 / 25$ & $24 / 25$ \\
\hline Doses requested & $3(0-5)$ & $3(0-5)$ \\
\hline Time to first request $(\mathrm{min})$ & $115(50-623)$ & $95(35-545)$ \\
\hline
\end{tabular}

minophen-codeine requirements from zero to six hours and zero to $24 \mathrm{hr}$ after meloxicam administration. Also, there was no difference between the local and the $i v$ group for the time from administration of meloxicam to the first request for acetaminophencodeine (Table II).

The 1-compartment model described the data better than other compartmental models as evaluated by Akaike/Schwarts Information Criteria, residual plots, predicted concentrations vs observed concentrations and with different methods of weighting.

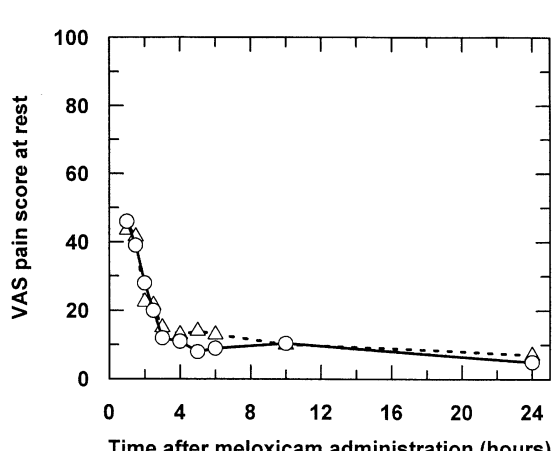

\section{$-\triangle$. Local adm}

$-\infty$ IV adm.

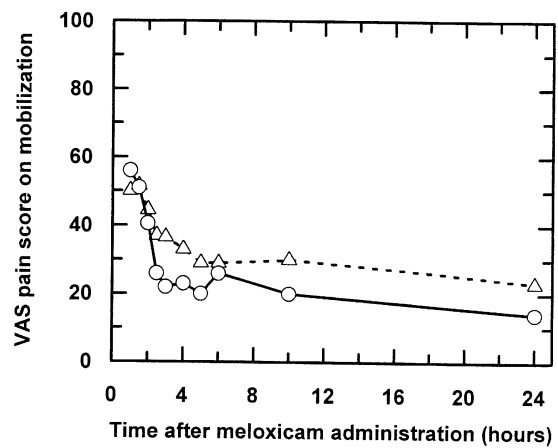

$-\triangle$ - Local adm

$-\infty$ IV adm

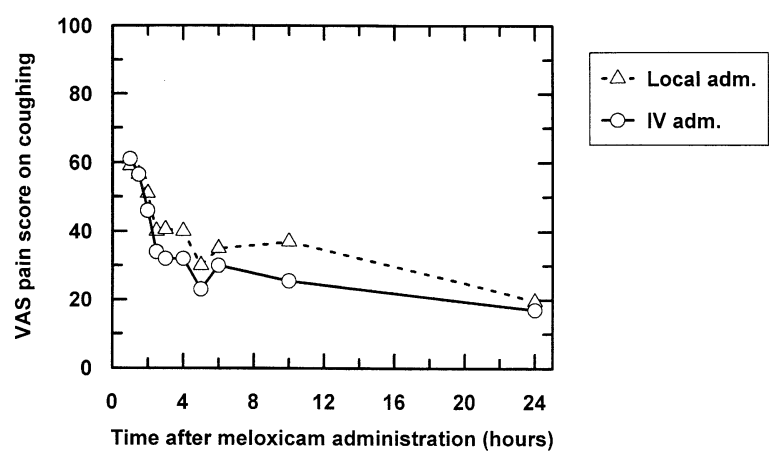

FIGURE 1 Postoperative visual analogue scale (VAS) pain scores following local and $i v$ administration of meloxicam. Pain scores were assessed at rest, on mobilization from the supine to the sitting position and on coughing. No significant differences between groups.

The mean time-concentration profiles zero to six hours and zero to $24 \mathrm{hr}$ after local and iv administration of $7.5 \mathrm{mg}$ doses of meloxicam are presented in Figure 2, and the pharmacokinetic parameters of meloxicam are shown in Table III. Following local administration of meloxicam the drug was absorbed into the systemic circulation after approximately three minutes and a mean $\mathrm{C}_{\max }$ value of $0.5 \pm 0.2 \mathrm{mg} \cdot \mathrm{L}^{-1}$ was achieved after $1.8 \pm 0.5 \mathrm{hr}\left(\mathrm{t}_{\max }\right)$. A drug plasma 
TABLE III The pharmacokinetic parameters of meloxicam $7.5 \mathrm{mg}$ after local and $i v$ administration (mean \pm SD)

\begin{tabular}{llllllll}
\hline & $\begin{array}{l}T_{\text {lag }} \\
(h)\end{array}$ & $\begin{array}{l}T_{\max } \\
(b)\end{array}$ & $\begin{array}{l}C_{\max } \\
\left(m g \cdot L^{-1}\right)\end{array}$ & $\begin{array}{l}t_{1 / 2} \\
(h)\end{array}$ & $\begin{array}{l}A U C \\
\left(m g \cdot h r^{-1} \cdot L^{-1}\right)\end{array}$ & $\begin{array}{l}\left.C L / F^{n}\right) \\
\left(L \cdot h r^{-1} \mathrm{~kg}^{-1}\right)\end{array}$ & $\begin{array}{l}V / F^{a)} \\
\left(L \cdot \mathrm{kg}^{-1}\right)\end{array}$ \\
\hline $\begin{array}{l}\text { Local group } \\
\text { iv group }\end{array}$ & $0.06 \pm 0.04$ & $1.8 \pm 0.5$ & $0.5 \pm 0.2$ & $53.1 \pm 19.8$ & $13.3 \pm 6.8$ & $0.1 \pm 0.03$ & $2.2 \pm 1.9$ \\
\hline
\end{tabular}

$\mathrm{T}_{\mathrm{lag}}=$ absorption lag time; $\mathrm{T}_{\max }=$ time to maximum concentration; $\mathrm{C}_{\max }=$ maximum plasma concentration; $\mathrm{t}_{1 / 2}=$ terminal elimination half-life; $\mathrm{AUC} C=$ area under plasma concentration-time curve; $\mathrm{V}=$ =volume of distribution; $\mathrm{CL}=$ clearance; $\mathrm{F}=$ bioavailability; $\mathrm{a})=\mathrm{CL}$ and $\mathrm{V}$ in the case of iv administration.
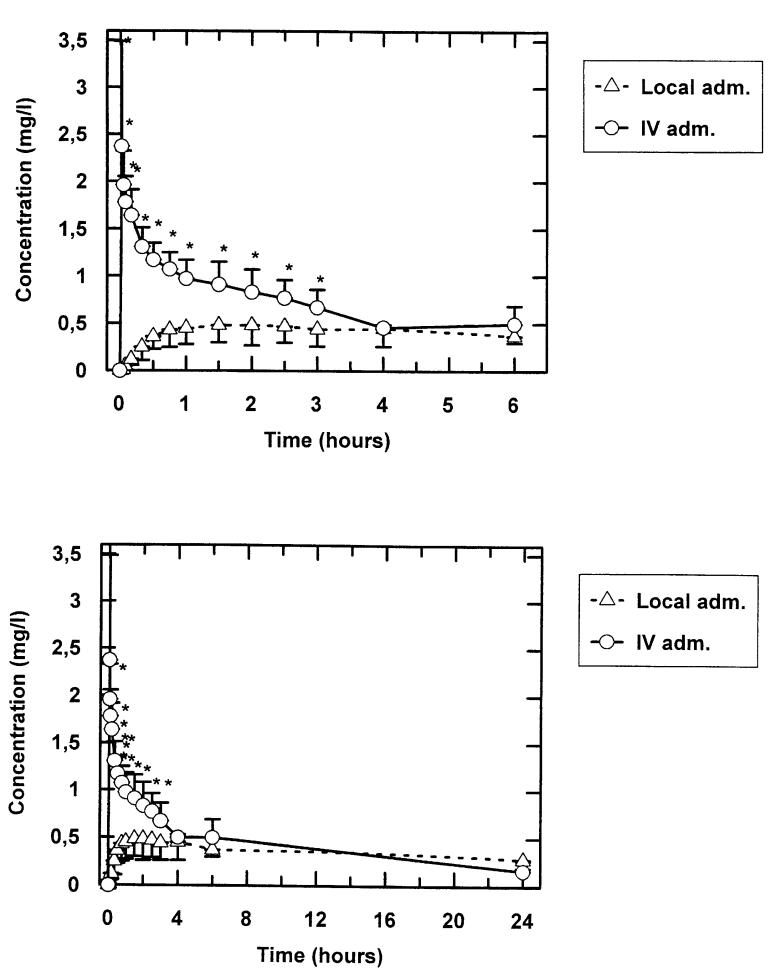

FIGURE 2 The mean time-concentration profiles zero to six hours and zero to $24 \mathrm{hr}$ after local and $i v$ administration of meloxicam. ${ }^{*} P<0.05$

concentration plateau of approximately $0.4 \mathrm{mg} \cdot \mathrm{L}^{-1}$ was then maintained up to $24 \mathrm{hr}$ after administration. Following iv administration of meloxicam drug plasma concentrations declined after a rapid distribution phase mean $\mathrm{C}_{\max }$ was $2.5 \pm 0.9 \mathrm{mg} \cdot \mathrm{L}^{-1}$. A relatively constant drug plasma concentration plateau of about $0.5 \mathrm{mg} \cdot \mathrm{L}^{-1}$ was achieved after four hours declining to about $0.2 \mathrm{mg} \cdot \mathrm{L}^{-1}$ at $24 \mathrm{hr}$. During the first three hours the mean plasma drug concentration was significantly lower after local than after $i v$ administration $(P<0.05)$ but after four hours plasma concentration profiles were almost identical (Figure 2).

All patients were observed for postoperative bleeding secondary to the use of meloxicam.

Only one patient in the $i v$ group had the dressing changed twice during the study period due to minor bleeding.

\section{Discussion}

This study showed no significant differences in pain scores and consumption of supplementary analgesics between local application and $i v$ administration of a single dose of meloxicam $7.5 \mathrm{mg}$ during the first $24 \mathrm{hr}$ after inguinal herniorrhaphy while mean plasma meloxicam concentration was significantly lower after local compared with $i v$ administration during the first three hours.

Several placebo-controlled studies have shown that systemic NSAIDs reduce post herniorrhaphy pain and use of additional analgesics.7,10,13,14 Local NSAIDs may have several advantages over their systemically administered counterparts, as they deliver high drug concentrations locally into affected tissues, while producing limited systemic absorption.

We found no statistically significant differences in pain scores at rest, during mobilization, and coughing between the local and the iv groups at six hours (primary end point) or at any time during the study period. Also, there were no differences between groups for the time from administration of meloxicam to first analgesic request or in the cumulative postoperative analgesic requirements at six hours or during the first $24 \mathrm{hr}$ after surgery.

There are five published studies examining the effect of WI with NSAIDs on postoperative pain after inguinal herniorrhaphy. ${ }^{7,8,10-12}$ In two of the studies, no differences were observed in postoperative pain scores and analgesic requirements between WI and $i m$ administration of tenoxicam $7.5 \mathrm{mg}^{8}$ and between WI and iv administration of ketorolac $30 \mathrm{mg},{ }^{10}$ respectively. In contrast to these studies, superior analgesia after locally applied NSAIDs have been reported in three studies. 
Significantly lower pain scores and analgesic use were found in the WI groups when comparing WI ketorolac $30 \mathrm{mg}$ and $i m$ ketorolac $60 \mathrm{mg},{ }^{7} \mathrm{WI}$ and $i v$ ketorolac $60 \mathrm{mg},{ }^{11}$ and WI and iv tenoxicam $10 \mathrm{mg} .{ }^{12}$

We also examined plasma concentrations of meloxicam after local and iv administration in order to establish whether the demonstrated efficacy of local application could be accounted for by systemic absorption of the drug or was more likely to be caused by local effect of the drug. We found that the maximum plasma concentration $\left(\mathrm{C}_{\max }\right)$ of meloxicam 7.5 mg was much lower following local application than $i v$ administration $\left(0.5 \pm 0.2 \mathrm{mg} \cdot \mathrm{L}^{-1}\right.$ and $2.5 \pm 0.9$ $\mathrm{mg} \cdot \mathrm{L}^{-1}$, respectively, and the plasma concentration profile was significantly lower following local application up to three hours after dosing.

The pharmacokinetic parameters of meloxicam after $i v$ administration in hernia patients are comparable to previous results in healthy volunteers. ${ }^{4,15,16}$ Meloxicam is bound to plasma proteins by more than $99.5 \%$. This agrees with our findings of a small volume of distribution of $4.2 \pm 0.7 \mathrm{~L} \cdot \mathrm{kg}^{-1}$ and a low clearance of $0.4 \pm 0.2 \mathrm{~L} \mathrm{hr}^{-1} \cdot \mathrm{kg}^{-1}$. The terminal elimination halflife was $19.2 \pm 6.4 \mathrm{hr}$. With respect to local application of meloxicam, pharmacokinetic parameters have not been investigated previously. Clearance and volume of distribution related to bioavailability were lower compared to $i v$ administration. The mean elimination half-

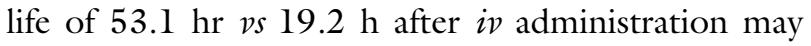
indicate that meloxicam was "stored" in the subfascial layer and slowly released in the systemic circulation.

Our results indicate a lack of any benefit in postoperative pain relief to concentrating the NSAID at the wound or to achieving high blood levels rapidly $(i v)$. In daily clinical work local administration of meloxicam may, theoretically, confer an advantage over systemic administration by eliciting lower incidences of systemic adverse effects normally related to higher drug plasma concentrations.

In our study the method of local administration of meloxicam was different from studies of WI with NSAIDs in inguinal herniorrhaphy. ${ }^{7,8,10-12}$ In the studies showing superior analgesia following WI with NSAIDs volumes of $10-20 \mathrm{~mL}$ were used for perfusion of the surgical wound. $7,11,12$ In the negative studies volumes of $40-50 \mathrm{~mL}$ were used. ${ }^{8,10}$ One study has shown that perfusion of the traumatized area in itself diminishes pain, whether the fluid used for perfusion is saline or a local anesthetic. ${ }^{17}$ Therefore, to avoid any possible therapeutic effect due to perfusion of the surgical wound, meloxicam $0.75 \mathrm{~mL}$ was applied directly along the entire length of the hernia wound, thus releasing the compound directly into affected tissues.
Meloxicam was administered in the subfascial layer since a study in hernia patients by Yndgaard et al. ${ }^{18}$ has shown that postoperative pain treatment with local lidocaine had a better effect when applied in the subfascial, rather than the subcutaneous, layer.

The study was considered adequately sensitive as the median VAS pain score in both groups at one hour after medication was between $50 \mathrm{~mm}$ and $60 \mathrm{~mm}$ during mobilization and coughing. Adequate sensitivity in trials of analgesics for acute pain is only achieved in patients experiencing at least moderate pain (VAS $>30$ $\mathrm{mm}$ ), since improvement in pain is difficult to detect if pain is absent or of low intensity. ${ }^{19,20}$ We did not include a placebo group because it has already been established that systemic NSAIDs reduce pain and analgesic requirements after herniorrhaphy. ${ }^{7,10,13,14}$ As well, meloxicam has demonstrated a significant reduction in postoperative pain scores compared with placebo after surgery. ${ }^{5}$ We wanted to distinguish between local and systemic drug effects.

In conclusion, following local application and $i v$ administration of meloxicam $7.5 \mathrm{mg}$ no differences in pain scores and consumption of supplementary analgesics were found between groups, while plasma concentrations from local doses were significantly lower than from iv doses within the first three hours. These results lend no support to any significant difference in postoperative pain relief following administration of meloxicam directly in the hernia wound compared with achieving high blood levels rapidly after iv administration.

\section{References}

I Vane J. Towards a better aspirin. Nature 1994; 367: 215-6.

2 Meade EA, Smith WL, DeWitt DL. Differential inhibition of prostaglandin endoperoxide synthase (cyclooxygenase) isozymes by aspirin and other non-steroidal anti-inflammatory drugs. J Biol Chem 1993; 268 : 6610-4.

3 Noble S, Balfour JA. Meloxicam. Drugs 1996; 51: 424-30.

4 Narjes H, Türck D, Busch U, Heinzel G, Nebmitz G. Pharmacokinetics and tolerability of meloxicam after i.m. administration. Br J Clin Pharmacol 1996; 41: 135-9.

5 Thompson JP, Sharpe P, Kiani S, Owen-Smith O. Effect of meloxicam on postoperative pain after abdominal hysterectomy. Br J Anaesth 2000; 84: 151-4.

6 Ferreira SH, Lorenzetti BB, Corrèa FMA. Central and peripheral antialgesic action of aspirin-like drugs. Eur J Pharmacol 1978; 53: 39-48.

7 Ben-David B, Katz E, Gaitini L, Goldik Z. Comparison of i.m. and local infiltration of ketorolac with and with out local anaesthetic. Br J Anaesth 1995; 75: 409-12. 
8 Mikkelsen SS, Knudsen KE, Kristensen BB, Linnemann MUS, Friis E, Dabl JB. Comparison of tenoxicam by intramuscular injection or wound infiltration for analgesia after inguinal herniorrhaphy. Anesth Analg 1996 83: 1239-43

9 Bosek V, Cox CE. Comparison of analgesic effect of locally and sytemically administered ketorolac in mastectomy patients. Ann Surg Oncol 1996; 3: 62-6.

10 Ben-David B, Baune-Goldstein U, Goldik Z, Gaitini L. Is preoperative ketorolac a useful adjunct to regional anesthesia for inguinal herniorrhaphy? Acta Anaesthesiol Scand 1996; 40: 358-63.

11 Connelly NR, Reuben SS, Albert M, Page D. Use of preincisional ketorolac in hernia patients. Intravenous versus surgical site. Reg Anesth 1997; 22: 229-32.

12 Lin C-F, Wong $K-L$, Chan $Y-L$, Wang J-M, Wu K-H, Wei T-T. Comparison of local infiltration of tenoxicam and intravenous tenoxicam for postoperative analgesia in herniorrhaphy. Acta Anaesthesiol Sin 1998; 36: 23-9.

13 Iles JDH. Relief of postoperative pain by ibuprofen: A report of two studies. Can J Surg 1980; 23: 288-90.

14 Dueholm S, Forrest M, Hjortsø E, Lemvigh E. Pain relief following herniotomy: a double-blind randomized comparison between naproxen and placebo. Acta Anaesthesiol Scand 1989; 33: 391-4.

15 Türck D, Busch U, Heinzel G, Narjes H. Clinical pharmacokinetics of meloxicam. Arzneim-Forsch 1997; 47 253-8.

16 Schmid J, Busch U, Heinzel G, Bozler G, Kaschke S, Kummwr M. Meloxicam. Pharmacokinetics and metabolic pattern after intravenous infusion and oral administration to healthy subjects. Drug Metab Dispos 1995 23: 1206-13.

17 Thomas DFM, Lambert WG, Lloyd Williams K. The direct perfusion of surgical wounds with local anaesthetic solution: an approach to postoperative pain? Ann R Coll Surg Engl 1983; 65: 226-9.

18 Yndgaard S, Holst P, Bjerre-Jepsen K, Thomsen CB, Struckmann J, Mogensen T. Subcutaneously versus subfascially administered lidocaine in pain treatment after inguinal herniotomy. Anesth Analg 1994; 79: 324-7.

19 Bjune K, Stubhang A, Dodgson MS, Breivik H. Additive analgesic effect of codeine and paracetamol can be detected in strong, but not moderate, pain after Caesarean section. Acta Anaesthesiol Scand 1996; 40: 399-407.

20 Collins SL, Moore RA, McQuay HJ. The visual analogue pain intensity scale: what is moderate pain in millimetres? Pain 1997; 72: 95-7. 